\title{
Modeling the Dietary Pesticide Exposures of Young Children
}

\section{FRANK R. PENNYCOOK, MA, EMILY M. DIAMAND, MSC, ANDREW WATTERSON, PHD, C. VYVYAN HOWARD, MB, CHB, PHD}

A stepped approach was used to assess the exposures of $1 \frac{1}{2}-4^{1} / 2^{-}$-year-old children in the United Kingdom to residues of pesticides (dithiocarbamates; phosmet; carbendazim) found in apples and pears. The theoretical possibility that the acute reference dose (ARD) was being exceeded for a particular pesticide/fruit was tested by applying a combination of maximal variability and maximum measured residue relative to an averagebody-weight consumer. The actual risk was then quantified by stochastically modeling consumption, from dietary survey data, with individual body weights, against published residue results for 2000-2002 and the variability of residue distribution within batches. The results, expressed as numbers of children per day likely to ingest more than the ARD, were in the range of 10-226.6 children per day, depending upon the pesticide and year of sampling. The implications for regulatory action are discussed. Key words: pesticides; dietary exposure; acute reference dose (ARD); apples; pears; dithiocarbamates; phosmet; carbendazim.

INT J OCCUP ENVIRON HEALTH 2004;10:304-309

$\mathrm{P}$ esticide residues in food have historically lagged far behind many comparable hazards as a cause for public health concern and action. The WHO and the FAO together started annual meetings focusing on food additives in 1956, but not until 1963 did pesticide residues receive the same treatment. The potential impact of pesticide residues in food on children has been even more neglected. This is surprising in the light of society's general concerns about the vulnerability of children and the fact that infants and children-infancy being defined as beginning at the 26th week of gestation-are not "small adults," The oversight may reflect the fact that the voices of consumers, families, parents, and environmental groups have, in

Received from Friends of the Earth (Trust), London, England (FRP, EMD); Occupational and Environmental Health Research Group, University of Stirling, Stirling, Scotland (AW); and the Developmental Toxico-Pathology Research Group, Department of Human Anatomy and Cell Biology, University of Liverpool, Liverpool, England $(\mathrm{CVH})$. The research was done at Friends of the Earth. Supported by Friends of the Earth Trust, England, Wales, and Northern Ireland.

Address correspondence and reprint requests to: Emily M Diamand, Friends of the Earth Trust, 26-28 Underwood Street, London N1 7JQ, England. the main, been excluded from the decision-making bodies on risk assessment and risk management, whereas those from industry have not.

In the United States, Congress in 1988 recognized the risks of such neglect and set up a study specifically to look at pesticides in the diets of infants and children. ${ }^{1}$ In the United Kingdom especially, but also at an international level, the subject remained neglected for longer. In 1990, the International Program on Chemical Safety published an environmental health criteria document on the principles for the toxicologic assessment of pesticide residues. The group that produced these principles was drawn from science and government and included a representative from Imperial Chemical Industries (ICI) but failed to include any NGO representative in its membership. Their criteria document recognized the limits of all mathematical models for pesticide residues used at that time but, when evaluating data, apparently made no reference at all to how such residues might affect children. ${ }^{2}$

More recently, some evidence has indicated that the increase in the incidence of behavioral disorders among children in industrialized countries could be in part related to prenatal exposure to pesticides ${ }^{3}$ and that subtle harm to the brain early in life may not become evident until much later. ${ }^{4}$ In addition, there is evidence to suggest that early exposure to pesticides could predispose individuals to pesticide sensitivity as adults. ${ }^{5}$ Analyses for acute risk from pesticides generally concentrate on young children, particularly toddlers, because they are considered to be especially vulnerable to pesticide residues in food. This is partly because children eat considerably more food per unit body weight than do adults; it has been calculated that, in proportion to their body weight, preschool children consume twice as many fruit and vegetables as adults do. ${ }^{6}$

Some action has been taken by governments to address this issue. In the United States, the 1995 Food Quality Protection Act requires special consideration to be given to childhood exposures when making regulatory risk assessments of pesticide residue exposures. In 1999, the European Commission set a combined maximum limit for all pesticides in baby foods at 0.01 $\mathrm{mg} / \mathrm{kg}$. However, this law applies only to processed baby foods, and dietary surveys show that the first solid food for one in five babies is pureed fresh fruit or vegetables, ${ }^{7}$ while by 18 months only $4 \%$ of children are 
still eating processed baby foods. ${ }^{8}$ In 1997, the United Kingdom's Chief Medical Officer produced advice that it is a "sensible precaution" to wash and peel fresh fruit and vegetables to reduce pesticide levels, before giving them to children ${ }^{9}$; however, this advice was recently withdrawn, in part due to internal concern that such a position "would undermine the credibility of the current regulatory system for pesticides." 10

\section{Rules and Regulations Applying to Pesticides: International and $U K$}

Various limits and measures apply to pesticide residues in food. The FAO/WHO working group on pesticide residues is the international body that sets thresholds for acceptable exposures, including the acceptable daily intake (ADI) and the acute reference dose (ARD). ${ }^{11}$ The ADI is envisaged as the maximum amount (in $\mathrm{mg} / \mathrm{kg}$ body weight per day) of each pesticide that can be consumed daily over a lifetime without ill effect. The ARD is the maximum amount that can be consumed on one occasion without ill effect, and it applies only to those pesticides that are known to cause acute toxic effects. As the ARD is a fairly new concept, there are a large number of pesticides for which an ARD has yet to be set.

The legal limit for pesticide residues in food, to which farmers and retailers are required to comply under law, is the maximum residue level (MRL). ${ }^{12}$ MRLs are set under U.K. law and EU law and also by the international body the Codex Alimentarius Commission. MRLs are trading standards, allowing food commodities containing pesticide residues to be traded across international borders. Although MRLs are set with reference to the ADI and the ARD, the Pesticides Committee of the Codex Alimentarius, which negotiates MRLs, is nevertheless dominated by industry representatives. At the 2000 meeting, eight countries included a representative from the pesticide industry in their delegations, in addition to the representatives of 23 pesticide companies who were already at the negotiations. ${ }^{12}$

\section{Residue Variation}

Under rules laid out by the Codex Alimentarius Commission, governments are required to routinely monitor pesticide residues in produce for compliance with the legal maximum residue limit (MRL). This requirement was originally envisaged as a trading measure, and analysis is therefore conducted on composite samples from trade lots. Data on the pesticide residues in individual fruits are not routinely generated, and until the 1990s it was assumed that the residues were evenly distributed in the produce, so that individual fruits would contain residues that were average for the composite sample. However, in 1996 the U.K. government undertook sampling of individual units of various fruits, which showed that pesticide residues were unevenly distributed and could be concentrated in individual items; for example, one individual apple contained cabaryl concentrations 13 times greater than the average, and in the case of imported pears, the residue concentration in an individual item was found to be 21 times greater than the batch average. ${ }^{13}$ Despite this, standard residue monitoring continues to be based on composite sampling, with consumer safety assessments based largely upon compliance with legal limits.

This variation raised concern about the adequacy of risk assessments used to examine exposures of consumers to pesticide residues in food, and it was established that a consumer could be exposed to residue levels in excess of the acute reference dose (ARD) from consumption of a single unit in which the residue was concentrated. ${ }^{14}$ An examination of the causes of this variation, at an international conference convened in 1998 , concluded that variation was not restricted to particular pesticides, ${ }^{15}$ while researchers concluded that the degree of variation was unrelated to the residue concentration of the composite sample. ${ }^{16}$

\section{Standard Methods}

Recent studies have used residue data for specific pesticides in particular foods to investigate the impact of variation on acute exposure to pesticide residues. Hamey $^{17}$ modeled the exposures of young children aged $1 \frac{1}{2}-4$ years to carbaryl in apples and pears, using data from sampling conducted on individual fruits. Using probabilistic modeling, which consisted of iterating a combination of a randomly selected consumption amount with a randomly selected pesticide residue level, it was predicted that on between $0.006 \%$ and $0.016 \%$ of consumption days there would be an intake of carbaryl above the acute reference dose. Peeling the fruit before eating reduced this to between $0.001 \%$ and $0.008 \%$. When we applied these results to the estimated U.K. population of 360,295 children in this age group who eat apples (based on the 2001 census and Gregory et $\mathrm{al}^{8}{ }^{8}$ ), the results of the carbaryl study represent between 22 and 58 children per day who would consume over the acute reference dose for carbaryl. Similar results were obtained by Hamey and Harris, ${ }^{18}$ who modelled apple and carrot consumption against triazophos residues from 1998. In their results, even with peeling, the acute reference dose for this pesticide was exceeded by a factor of ten by $0.146 \%$ of toddlers eating apples each day, or 526 children, and by $0.025 \%$ of toddlers eating carrots each day, or 108 children nationwide.

For these reasons, this research has focused on the potential pesticide residue exposures of young children. Apples and pears were chosen because national dietary survey data indicate that over the course of a week, approximately half of all children aged $1 \frac{1}{2}-4^{1} / 2$ eat some quantity of apples and pears. ${ }^{8}$ 
In order to address the risks from short-term exposures to pesticide residues in food, it is first necessary to determine whether, taking pesticide residue variation into account, it is possible for the acute reference dose (ARD) to be exceeded at current levels of residues. Data were taken from the UK Pesticides Residues Committee's published monitoring results ${ }^{19}$ for apples (2000/01/02) and pears (2000/2002). Only data from recent years were used because pesticide uses on these crops change over time and recent data were felt to most accurately reflect the current situation.

Relating published pesticide residue monitoring results to the pesticide residues on individual fruits is not straightforward because of the way in which monitoring is conducted. The standard method, as laid out by the Codex Alimentarius Commission, for measuring pesticide residues in produce is to analyze the residues in a comminuted mixture derived from a sample of approximately $1 \mathrm{~kg}$ (ten fruits or vegetables, or five in the case of larger produce). Data on the pesticide residues in individual items are not routinely generated.

As a result of variation, the possibility exists that the entire residue in the sample mixture was originally concentrated in only one of the ten fruits. Based on this assumption, the World Health Organization has recommended that in risk assessments, the variability factor applied to composite sample averages should be ten for medium-sized produce and five for large produce. However, at an international conference in 1998, based on an examination of variation across a range of produce, it was suggested that most variation would be in the range of one to six times the average, and that the upper percentile (97.5th percentile) would show variation of seven to ten times. ${ }^{15}$

\section{A PROPOSED NEW METHOD}

It becomes possible for the acute reference dose to be exceeded when a combination of a high residue level and a high variability factor occurs. An initial screening was conducted on published residue results in order to establish whether this is a possibility.

The theoretical maximum residue level arises in the worst case where the variability factor is 10 . In this case the residue is concentrated into one fruit. If the average residue in a batch of ten fruits, as published, is $R \mathrm{mg} / \mathrm{kg}$ then the possible maximum concentration is $10 R \mathrm{mg} / \mathrm{kg}$.

If $W \mathrm{~kg}$ is the weight of the affected fruit item, it contains $10 R W \mathrm{mg}$ of residue. Finally, suppose the fruit to be eaten by a consumer of body weight $B \mathrm{~kg}$. The consumer's exposure is $10 R W / B \mathrm{mg} / \mathrm{kg}$.

For the screening process, average fruit weights and average consumer body weights were used. When the calculated theoretical maximum exposure was higher than the acute reference dose there was a possibility of exceeding the ARD if the necessary combination of factors were to occur.
Following Codex Alimentarius protocols, we assume that the test sample consists of ten fruits and, in the absence of data on the size distribution of fruit sampled in residue testing programs, we have taken average weights of $112 \mathrm{~g}$ for apples and $150 \mathrm{~g}$ for pears, as used by the U.K. Pesticides Safety Directorate in its analyses. ${ }^{20}$ The formula can be used to establish whether detected residues have exceeded this threshold for the most vulnerable consumers, in this case young children, using a body weight of $14.5 \mathrm{~kg}$, which is the average weight of children who ate apples and pears in the national dietary survey of children aged $1 \frac{1}{2} 2^{-4} /{ }_{2}$ years. ${ }^{8}$

The results of this initial screening process are shown in Table 1. The concentrations of residues in single fruits will only rarely vary by as much as ten times the composite average and, for the ARD to be exceeded, the high-residue fruit would have to be eaten by a child who was eating a large quantity of fruit in a day, and these children make up only a small proportion of the population. The next step is to establish whether this potential risk is likely to be realized.

\section{Estimating Exposure}

The initial screen indicates only whether or not the ARD for a particular pesticide in a particular batch of fruit could be exceeded. In order to model the probable rates of exposure within the population, we need to assign a residue exposure for each consumer within the modeled population. Individual exposure on each occasion can be expressed as $R v E$, where $R$ is the average residue level of the tested sample, $v$ is the variability factor, and $E$ is the weight of fruit eaten by the consumer.

Hamilton $^{21}$ suggests that studies of residues on individual fruits have generally found the residues to be distributed log-normally. Hill and Reynolds ${ }^{16}$ examined over 100 studies of variability and concluded that the log-transformed distribution was normal, with mean of 1.2168 and standard deviation of 0.3815 . The 97.5 th percentile of this distribution is 7.14 , which is consistent with the practice of using $v=7$ to represent the 97.5th percentile of variation (PSD). So our model allows variability of over 7 to occur, with low probabilities determined by the log-normal distribution. Values greater than 10 are capped because in a sample of ten fruits it is not possible to observe a variability of more than 10. The "worst case" is for the entire residue to be concentrated in a single fruit, and due to the large number of iterations this is certain to occur, although only with an appropriately low probability.

The individual consumption amounts for this model are taken from fruit consumption recorded in the national dietary survey of 1859 children aged $1 \frac{1}{2}-4^{1} / 2$ years, in which parents kept a diary of what each child ate for four days. Using linked data from this survey, we can create a consumer profile, made up of the amount of fruit eaten by each child and the weight of that child. 


\begin{tabular}{|c|c|c|c|c|c|c|}
\hline $\begin{array}{c}\text { Year/ } \\
\text { Quarter }\end{array}$ & Pesticide & Fruit & ARD & $\begin{array}{l}\text { Threshold for } \\
\text { Possible ARD } \\
\text { Exceedance }\end{array}$ & $\begin{array}{l}\text { Maximum } \\
\text { Residue } \\
\text { Found }\end{array}$ & $\begin{array}{c}\text { Maximum } \\
\text { Exposure } \\
\text { (\% ARD) }\end{array}$ \\
\hline $2000 / 4$ & Dithiocarbamates & Pears & 0.04 & 0.387 & 2.3 & 595 \\
\hline $2002 / 2$ & Phosmet & Pears & 0.02 & 0.193 & 0.5 & 259 \\
\hline $2002 / 4$ & Dithiocarbamates & Pears & 0.04 & 0.387 & 1.0 & 259 \\
\hline $2000 / 4$ & Phosmet & Pears & 0.02 & 0.193 & 0.5 & 259 \\
\hline $2001 / 4$ & Carbendazim & Apples & 0.04 & 0.518 & 0.7 & 135 \\
\hline $2002 / 2$ & Dithiocarbamates & Pears & 0.04 & 0.387 & 0.5 & 129 \\
\hline $2000 / 4$ & Dithiocarbamates & Apples & 0.04 & 0.518 & 0.6 & 116 \\
\hline $2002 / 4$ & Dithiocarbamates & Apples & 0.04 & 0.518 & 0.4 & 77 \\
\hline $2001 / 4$ & Dithiocarbamates & Apples & 0.04 & 0.518 & 0.3 & 58 \\
\hline $2002 / 2$ & Carbendazim & Apples & 0.04 & 0.518 & 0.3 & 58 \\
\hline $2002 / 2$ & Carbendazim & Pears & 0.04 & 0.387 & 0.2 & 52 \\
\hline $2002 / 4$ & Carbendazim & Pears & 0.04 & 0.387 & 0.2 & 52 \\
\hline
\end{tabular}

*Maximum exposures greater than $100 \%$ indicate cases in which there is potential for the ARD to be exceeded by young children eating a single apple or pear.

In this way we can account for any relationship between consumption and weight. We limit the models to single fruits only because, while two or more different fruits could be consumed by chance both containing levels of residue that together lead to an exceedance, survey data indicate that in only $1 \%$ of cases do children who eat apples also eat pears on the same day. ${ }^{7}$ This simplification is conservative, as it is likely to lead to an underestimate of the numbers affected, although not by an appreciable amount.

A standard method of estimating exposures is Monte Carlo modelling, which uses a randomized procedure to select data from a sample. The residues in individual fruits and the consumption patterns of consumers are represented by the best available sampled data, and an iterative process is used to simulate repeated consumption by members of the population over a period of time. Various studies have recently been published as the outputs of an EU-funded Monte Carlo project, and these help to create a general formal framework for modeling studies of this type. McNamara et al. ${ }^{22}$ describe a software design that can be configured to meet the differing requirements of pesticide, nutrient, and additive modeling, and also the lack of or availability of various types of data input. The design has the added advantage of being based on widely used free software tools, including PHP and MySQL. Our own modeling program can be seen as a special case of the McNamara general framework. Boon et al. ${ }^{23}$ report the results of a "duplicate diet" study in The Netherlands, in which duplicate portions were prepared of all the food items consumed by the surveyed infants. The duplicate portions were then assayed in a laboratory to provide a more accurate assessment of the pesticides actually consumed. By comparing both the "real intake" (measured from the duplicate portions) and the "point estimate" (i.e., the worst-case value given by applying maximum known residue to 97.5 th-percentile consumption amount) with the results obtained from probabilistic modeling, the authors were able to confirm that probabilistic modeling has validity in terms of its agreement with directly measured values.

The number of cycles to process was calculated from the number of individuals in the population and the period of the consumption studies. From census figures, we know that the total population of children $1 \frac{1}{2}-4^{1} / 2$ years old is $2,119,400$. Of these, the dietary survey found that the proportion likely to eat a pear on a given day was 0.02866, resulting in an estimated 60,700 individuals eating pears each day. Similarly, the proportion eating apples on any one day was 0.1952 , resulting in an estimated population of 413,800 apple eaters per day.

Given that residue levels in batches of fruit are variable, the likelihood of exceeding the ARD is greatest when the fruit with the highest residue is eaten. Our model simulates only these events, using the published residue figures for batches of ten fruits. Of the 60,700 individuals eating pears and 413,800 eating apples, one in ten will be eating the "worst" pear or apple from some batch. The others will eat apples or pears that are not the worst in their batches. Therefore, we ran each model for 6,073 iterations for pears and 41,378 iterations for apples. On each cycle, we selected a residue level at random from the published results, representing a new sample of fruit. Under the assumption made 
TABLE 2. Results of Modeling Pesticide Exposures from Consumption of Apples

\begin{tabular}{lccccc}
\hline Pesticide, Year/Quarter & $\begin{array}{c}\text { No. of } \\
\text { Residue } \\
\text { Values }\end{array}$ & $\begin{array}{c}\text { ARD } \\
(\mathbf{m g} / \mathbf{k g} \text { bw) }\end{array}$ & $\begin{array}{c}\text { Maximum Residue } \\
\text { Found in } \\
\text { Samples (mg/kg) }\end{array}$ & $\begin{array}{c}\text { MRL } \\
(\mathbf{m g} / \mathbf{k g})\end{array}$ & $\begin{array}{c}\text { ARD Exceedances } \\
\text { per Day: Average } \\
\text { Over Ten Runs }\end{array}$ \\
\hline Carbendazim, 2000/4 & 144 & 0.04 & 0.8 & 2 & 32.5 \\
Carbendazim, 2001/4 & 72 & 0.04 & 0.7 & 2 & 17.9 \\
Dithiocarbamates, 2000/4 & 130 & 0.04 & 0.8 & 3 & 10.0 \\
\hline
\end{tabular}

above we know that one consumer will encounter whichever of the ten fruits in this sample has the highest residue. The variation of residue levels in the batch was represented by a variability factor chosen randomly from a pool generated beforehand. As outlined above, the variability factors followed a log-normal distribution. Finally, to determine exposure, a consumer profile consisting of a consumption amount and a body weight was selected randomly from the results provided by the National Dietary survey.

The calculations were carried out using a modeling program written in $\mathrm{C}$, the source code and documentation for which are available from the authors. The pesticide exposure in $\mathrm{mg}$ was divided by the consumer's weight and the dosage can be compared directly with the ARD. The model program reports the numbers of exceedances that occur across all cycles, and also the maximum residue level, variability factor, consumption amount, and exposure found during the model run. For each pesticide/food combination the model was run ten times in order to give an indication of variability.

It is worth noting that this model is conservative and that these results deliberately do not overestimate the number in the population who will exceed the ARD. Although the following factors are likely to make only a small difference to the number of exceedances, it is possible to eat more than one fruit and get residues from both, which we have not modeled, and it is also possible to get residues of the same compound from other foods, and we have not modeled this.

\section{RESULTS}

The results of the initial screening process are shown in Table 1 .

\section{Results of the Modeling Process (Tables 2 and 3)}

In the case of apples, 1,337 consumer profiles are provided from the national dietary survey. Because this model does not account for consumption of more than one apple, consumption is capped at $112 \mathrm{~g}$, although consumption levels greater than this do occur. For pears, the number of consumption profiles is much fewer, at 194. Consumption is similarly capped at $150 \mathrm{~g}$, or one pear.

\section{DISCUSSION}

Our results are consistent with results of previous analyses such as those of Hamey ${ }^{17}$ and Hamey and Harris. ${ }^{18}$ They indicate that variation in pesticide residues is sufficient to cause individual children to experience occasional exposures to pesticides at levels in excess of accepted safety thresholds, even in cases where the MRL is not regularly breached. The modeling shows that this cannot be regarded as a highly unlikely event, because the large numbers of produce and individuals involved ensure that each day some will experience the necessary combination of factors. The children affected are those who eat sufficient quantities of apple or of pear on a given day, and in addition select by chance one of the fruits with an especially high level of pesticide residue. These children are not a special group who always eat lots of apples or pears, but rather represent the consequence of the variability of the diet; from day to day the children eating larger quantities of fruit are likely to be different individuals.

It appears that regulatory action would not have been triggered in the majority of the cases because the MRL was not exceeded. Exposure to pesticide residues above the acute reference dose does not, of course,

TABLE 3. Results of Modeling Pesticide Exposures from Consumption of Pears

\begin{tabular}{lcccrr}
\hline Pesticide, Year/Quarter & $\begin{array}{c}\text { No. of } \\
\text { Residue } \\
\text { Values }\end{array}$ & $\begin{array}{c}\text { ARD } \\
\text { (mg/kg bw) }\end{array}$ & $\begin{array}{c}\text { Maximum Residue } \\
\text { Found in } \\
\text { Samples (mg/kg) }\end{array}$ & $\begin{array}{r}\text { ARD Exceedances } \\
\text { (mg/kg) }\end{array}$ & $\begin{array}{r}\text { MRer Day: Average } \\
\text { Over Ten Runs }\end{array}$ \\
\hline Carbendazim, 2000/4 & 52 & 0.04 & 0.6 & 2 & 19.0 \\
Dithiocarbamates, 2000/4 & 52 & 0.04 & 2.3 & 3 & 205.2 \\
Dithiocarbamates, 2002/2 & 35 & 0.04 & 0.5 & 3 & 12.7 \\
Dithiocarbamates, 2002/4 & 37 & 0.04 & 1.0 & 3 & 10 \\
Phosmet, 2000/4 & 52 & 0.02 & 0.5 & 10 & 102.6 \\
Phosmet, 2002/2 & 75 & 0.02 & 0.5 & 10 & 48.4 \\
Phosmet, 2002/4 & 195 & 0.02 & 0.6 & 226.6 \\
\hline
\end{tabular}


necessarily translate directly into harm, because there is an in-built margin for error in the acute reference dose. But, while it is probable that this will provide many children with some protection, there is still little clarity as to by how much the ARD can be exceeded before the most sensitive individuals experience adverse effects. Nevertheless, high levels of exposure in a day, or over a few days, should not be dismissed lightly, and the ARD is there to protect those who might be particularly vulnerable.

As far as we are aware, there has not been any societal discussion about what would constitute an acceptable number of young children exposed to pesticides above the acute reference dose. In the absence of this, the precautionary approach indicates that legal limits on pesticide residues in food should be set such that they take into account the effect of variability on exposure..$^{24,25}$

\section{References}

1. National Research Council. Pesticides in the diets of infants and children. National Research Council, Washington, DC: National Academy Press, 1993.

2. International Program on Chemical Safety. Principles for the toxicological assessment of pesticide residues in food. Environmental Health Criteria 104. Geneva, Switzerland: World Health Organization, 1990: 76-83.

3. Landrigan PJ. Pesticides and polychlorinated biphenyls (PCBs): an analysis of the evidence that they impair children's neurobehavioural development Molec Genetics Metab. 2001;73:11-7.

4. Weiss B. Pesticides as a source of developmental disabilities. Mental Retardation and Developmental Disabilities Research Reviews 1997; 3: 246-56.

5. Ericksson P, Talts U. Neonatal exposure to neurotoxic pesticides increases adult susceptibility: a review of current findings. Neurotoxicology. 2000; 21: 37-48.

6. Lawrie CA. Different dietary patterns in relation to age and the consequences for intake of food chemicals. Food Additives and Contaminants. 1998; 15 suppl; 75-81.

7. Mills A, Tyler H. Food and nutrient intakes of British infants aged 6-12 months. London, England: Her Majesty's Stationary Office, 1992

8. Gregory J, Collins D, Davies P, et al. The National dietary and Nutritional Survey: children aged $1 \frac{1}{2}$ to $4^{1} / 2$ years. London, England: Her Majesty's Stationary Office, 1995 .

9. Ministry of Agriculture, Fisheries and Food, UK. 1997. News Release $(83 / 97)$.
10. Advisory Committee on Pesticides. Review of the need for CMO's advice on washing and peeling fruit and vegetables. 2001. ACP meeting paper ACP 20(287/2001).

11. CAC/GL33 Codex Alimentarius. Recommended methods of sampling for the determination of pesticide residues for compliance with MRLs. <www.codexalimentarius.net/web/standard list.jsp>

12. FAO/WHO. Joint FAO/WHO Food Standards Programme Codex Alimentarius Commission Twenty-Fourth Session Geneva, 2-7 July 2001; Report of the thirty-second session of the Codex committee on pesticide residues, The Hague 1-8 May 2000. Geneva, Switzerland: FAO/WHO. 2001.

13. Pesticides Safety Directorate. Unit to unit variation of pesticide residues in fruit and vegetables. London, England: Department of the Environment, Food and Rural Affairs, 1997.

14. Advisory Committee on Pesticides. Consumer Risk Assessment of Insecticide Residues in Carrots. Disclosure Document PSD/ MAFF, 1995.

15. Pesticides Safety Directorate. Report of the International Conference on Pesticides Residues Variability and Acute Dietary Risk Assessment, 1-3 December 1998, York, U.K. PSD, 1999.

16. Hill ARC, Reynolds SL. Unit-to-unit variability of pesticide residues in fruit and vegetables. Food Additives and Contaminants. 2002;19:733-47.

17. Hamey PY. A practical application of probabilistic modeling in assessment of dietary exposure of fruit consumers to pesticide residues. Food Additives and Contaminants. 2000;17: 601-10.

18. Hamey PY, Harris CA. The variation of pesticide residues in fruits and vegetables and the associated assessment of risk. Regulatory Toxicol Pharmacol. 1999;30:S34-S41.

19. Pesticides Residues Committee. Annual Report of the Pesticide Residues Committee, 2000. PRC, 2001.

20. Advisory Committee on Pesticides. Future developments of exposure models to calculate potential intakes of pesticide residues by UK consumers. Paper presented to committee, 6 September 2000.

21. Hamilton D. Making the best use of available residue data for acute intake assessment. Food Additives and Contaminants. 2000;17: 563-8.

22. McNamara C, Naddy B, Rohan D, et al. Design, development and validation of software for modelling dietary exposure to food chemicals and nutrients. Food Additives and Contaminants. 2003;20 supp1: S8-S26.

23. Boon PE, van der Voet H, van Klaveren JD. Validation of a probabilistic model of dietary exposure to selected pesticides in Dutch infants. Food Additives and Contaminants. 2003: 20 suppl 1; S36-S49.

24. European Environment Agency. Late Lessons from Early Warnings: The Precautionary Principle 1896-2000. Environmental Issue Report No 22. Copenhagen, Denmark: EEA, 2001.

25. Raffensberger C, Tickner J (eds). Protecting the Public Health and the Environment: Implementing the Precautionary Principle. Washington, DC: Island Press, 1999. 